\title{
Towards a journalism theory: Muniz Sodré in search of the elements that compose the medium issue.
}

\section{PABLO LATGNIER}

SODRÉ, Muniz (2009).

The narration of fact: notes for an issue theory. Petrópolis, RJ: Ed. Vozes, 287 p.

\begin{abstract}
:
The purpose of this academic review is to map Muniz Sodré's most recently book: the narration of fact: notes for an issue theory, highlighting the leading points analyzed by the author in each of its three chapters. So, this texts tries to investigate how much original and relevant Sodré's study may be as a new contribution to elaborate a journalism theory.
\end{abstract}

Key words: Discourse; Journalism; Narrative; Fait-divers; Whodunit.

"A complete translator of his era": defined like that by the researcher Raquel Paiva in a former text that she wrote about his intellectual history (Paiva, 2004: 200), Muniz Sodré may be considered as a unique academic author. Owner of an extensive literary-academic work, part translated and published in foreign countries, Sodré is able to pronounce so much orally - through his classes and conferences - as into written form - through his more than 30 books already published reflexive words about a diversity of topics related to the theoretic sphere of Social Communication.

To establish bridges and to understand the similarities and differences between historical moments, different ways of affection, sensitivity, rationality and bond is what this author proposes and, particularly right now, in his most recently book, he points out his efforts and well-known knowledge towards a detailed analysis of journalism as a narrative practice, composed by a discourse that involves the materiality of journal, the symbolic condition of ideologies attached to this practice (which had changed in the last three centuries), in addition to sensitive elements that guarantee a proximity between the lecturer and the journal, establishing parameters to the journalistic practice as a construction of narratives about everyday.

The referred book is divided into three great chapters. The first part, titled "The discourse of the issue", may be considered the most "thick" into theoretical exposition density. This is the part of the book into which Muniz Sodré discusses determined terminologies, looking for presenting a clear 
delimitation (nor univocal or deterministic) that open possibilities for future studies to use wellconstructed conceptual categories related to the comprehension of the aspects involved into journalistic narrative. Such conceptual categories like: "fact", "issue", "news".

As the author defines into the book's introduction,

even that the journal does not limit itself to news-reporting in the strict sense of the word, this communicative form has ballasted in the two last centuries the modern idea of journalism, in a way that it gives shape to the construction and maintenance of all the mythology about neutrality that is attached to a commodity and that, hence, sustained the coefficients of public confidence in the reports (Sodré, 2009: 14).

In this sense, Sodré concentrates his theoretic discussion on the appreciation of the aspects that offer "newsworthiness" to the facts, understanding these as "state of things", based on Kant's notion: "The world of facts - to what we may also call 'state of things' - is the world of empirical experience, which means of contingent relations, of phenomena that may occur or not, outside any necessary order" (Sodré, 2009: 28). Related to this discussion, the author also presents Wittgenstein`s distinction between "fact" and "thing", the first being "a conceptual objectification of phenomena's reality" (Sodré, 2009: 29), while the "thing" configures itself as the element that "serve to fulfill the objective reality of the consciousness phenomena" (Sodré, 2009: 28). The discussion also points out, briefly, the differences between occurrences of type casus facti (cases of fact) and casus ficti (cases related to the imaginary), besides the distinction between "generic facts" and "social facts". The latter are presented as a main character to participate of human activity and of socius as existential space, where is possible "to-be-together-with-the-other" (Sodré, 2009: 29).

The facts are selected from the day-by-day to integrate the dispositive of "journal", becoming news from a side view that privilege those that constitute "issues" in the city or country where they are published. The argumentation about the constitution of the "issue" is one of the densest in the book, occupying almost forty pages and presenting different authors and examples. This discussion includes the differentiation between "medium issue" and "existential issue". It is important to notice the complexity of this topic, because the "issue" is what ensures "newsworthiness" to determinate "social facts" into the journalistic ruling. "Issues" are aural in a Benjaminian sense and represent irruptions in the "here-and-now" of the subjects and social situations. The "issue quality" of a fact is guaranteed by a relational situation of this with those material, symbolic and effective (sensitive) aspects of citizen day-by-day or that extended public sphere that emerge from the massive journalism since the beginning of the $19^{\text {th }}$ century. A fundamental element to the understatement of what becomes the press journalism as a informational/ideological dispositive and the own journalistic activity as a praxis 
of the contemporary metropolis and the modern public sphere, the "issue" configures, in this book, the lead keyword of the discussion (together with the concept of "narrative", as will be seen next): it is this that singularize the facts from the temporality and from other geographical/political/historical specificities. This way, Sodré presents the idea (retaking it from his anterior book, The sensitive strategies) that the "issues" can not be explained only in a rational way, but one should have take in count the indicial quality contained in its sensitive aspects; the proximity between a fact, for example, and other from a determinate city: "The sensitiveness is an important category to understand this operation, once that the local and the singular induct emotionally to the identification of the lecturer with the issue that, communicated in an abstract or conceptual way, may be not mobilize the public attention" (Sodré, 2009: 58). In this sense, as the author says, the journalism may be situated as something that stands between common sense and a systematic knowledge. Besides, the "topicality" is considered by Sodré as a fundamental element on the choice of determinate social facts to become medium issues.

The "news" itself is the way that selected "social facts" become issues in journal 's physical structure. It consists in a format that implies a proper narrative in which the lead and the fait-divers become important aspects (although non-exclusive, nor essential). The news are the housing of the media issue into "press journal" dispositive and its narrative presents a proper rhetoric, consistent with the real reference in which the news supposedly are based on. So it is a narrative about real social facts marked as issues because of the singularity that their temporal and geographical/political/historical elements point into metropolis everyday. The news search for topicality and a narrative form of easy identification of the main aspects to be informed to the reader. Peculiar to North American journalism since $19^{\text {th }}$ century`s second half and being constituted as a pattern to occidental journalism (and nowadays globalized) in the $20^{\text {th }}$ century, the news does not represent the total form of journalism, but are utilized almost as a synonym of this professional practice on everyday use. The discussion about the "news" undertaken by Muniz Sodré shows historically how they were build as form and value in which refers to journalistic narrative, presenting the characteristics of the fait-divers on issues punctuation and discussing the generic characteristics that make a social fact become more or less semiotic and culturally marked into journalistic interest.

Still in this first part the author talks about the rhythmic punctuation that the media issue operates in the singling of social facts into their journalistic updating. He points out two rhythmic levels: "into a first level, what gives rhythm to the everyday are the routines written individual and collectively on social life; into a second level, the issues that punctuate - into different scales of intensity - this routines" (Sodré, 2009: 90). Sodré even delineates an analogy on music and its rhythmic question, concluding that "the informational system scans the occurrences, which means 
that it gives them a metrical value in the same way as one may does with musical notes or with poems syllables, according to a technical appreciation about the degree of relationship between the social body and the guided occurrence" (Sodré, 2009: 91).

Based on the question of the rhythmic punctuation, Sodré ends the chapter discussing "the time mutations", presenting a panoramic view of post-modernity as it was described by Lyotard in the late 70 's, as a society in which the capitalist system turned its logic from the production to the consumption, which operates directly on our relation with time. There is a devaluation of memory and a preference to the excess of topicality, a kind of eternal updating embodied by "informational nymphomaniac". It consists in a moment that "the consumption does not be understood as a simple finalistic moment of productive rationality anymore, but as a true system that relates the subject not only to belongings and use values, but to the world as a totality" (Sodré, 2009: 104). At this point, Sodré hangs an interesting discussion in respect of journalism into cyberspace, presenting examples that demonstrate how much there is a significant change between this and the journalism that is traditionally made into newspapers: "this is the reality of public information under the influx of neoliberal age. It fades out the classical idea of the press as a 'culture promoter agent '" (Sodré, 2009: 115). And the author complements: "in this new system, the old press redefines itself as part of what has been called 'contents industry', which means a deterritorialized production of programs to telematic networks." (Sodré, 2009: 118). Following his own argument, Muniz Sodré retakes his concept of "media bios" (formulated in his book Anthropological of the mirror), in addition of mentioning Kerckove, to affirm that the sensitive today predominates over the argumentative logic that so much characterized the bourgeois press of the $18^{\text {th }}$ and $19^{\text {th }}$ centuries. From the television and the telematic networks, the mutation was occurring to the point that nowadays, according to Sodré, the journalism due to this present state is "predominantly indicial" (Sodré, 2009: 129). Referring to Baudrillard, Sodré remembers that "the information of the event is nowadays substituted by the event of the information" (Sodré, 2009: 134). And he ends the chapter demonstrating how much the discourse about the absolute journalism objectivity does not support itself anymore and that, in fact, there is a weak objectivity, which does not mean that the journalism had lost completely its relation to the audience, in terms of credibility.

At this point starts the second half of the book, entitled "The narrative experience", in which the author theorizes about the relations of similarity and difference between the Romanesque and the journalistic narrative, assuming a certain degree of fictionalization in the elaboration of the news, even that there is a search for a mirror of the real in their production. The second chapter presents the journalistic information as part of a discourse, affirming that "the news (...) is a social-discursive genre" (Sodré, 2009: 138). This way, in this chapter Muniz Sodré uses discourse analysis and historical 
elements to operate the distinction and to admit similarities between literary and journalistic narratives. This is a chapter with lots of examples taken directly from journals that serve to exemplify the characteristics presented by the author when he refers to determinate typing of the journalism text. The chronicle, for instance, appears as a mid-term between the journalistic and literary narrative. Another type of text presented is the suelto, a kind of mini-chronicle from Spanish origins. The discussion permeates the development of rhetoric and the classical narratives until arrive to the modern experience of narrative analyzed by Walter Benjamin and the post-modern language games presented by Lyotard.

In this sense, Sodré affirms that the culture of book and, consequently, the press journalism meant the primacy of the statement over the enunciation. The author yet discusses the relation between the narrative and social sciences. However, he presents the vision that the contemporariness substitutes the symbolic density for the transparency in which is related to the information. So, the author writes about the New Journalism as form of non-fiction literary narrative. He also demonstrates the hybridization of journalistic narrative with other like the info-graphic and the draws, even remembering the constant presence of comic histories as a factor of attraction to the North American newspapers's readers since the $19^{\text {th }}$ century.

In one of this chapter's topics, Sodré discusses what today means to narrate based on the studies area known as "narratology": "The basic scheme of a narrative sequence is something as: initial situation - complication - reaction - resolution - final situation - evaluation or moral of the story" (Sodré, 2009: 204). Next, the author presents different ways of narrating the news, based on examples taken from journals. From the lead to the "nose-to-wax", the author also deals with the narration viewing the issue 's "colored" elements, the "creation news" and the different possible "angles" into journalistic narration building. After that, the author presents cases of journalism fraud and characteristics of sensationalism, ending this chapter with an explanation about features and faitdivers, sustaining that the emotional factors involved on their elaboration are essential to the understatement of their importance into the building of journalistic narrative.

The third chapter, entitled "The fact in red-blood", is the most affectionate of the book. Interesting is the form how this book was written by the author: at each chapter, the lecture becomes softer, less thick from a theoretic point of view and more pleasant in terms of lecture for the quantity of literary-journalistic examples. It is the only chapter that has its subdivisions appearing in the book summary, pointing out its importance (at least on emotional terms) to the author. The most fundamental things to be discussed in terms of journalistic semiosis and its socio-cultural and discursive implications have been already done in the previous pages. From now on, this chapter search for relating the whodunit literacy with the journalistic narrative, finding into fait-divers the 
necessary supporting point for the analysis. The chapter's emotional accent is showed since its first pages, for instance on that part in which Muniz Sodré places to the reader, on an autobiographic shade, what lecture meant to him on his adolescence:

All of this had happened through the end of childhood to the adolescence, when I focused particularly on detective fiction. At the time, my biggest picture of personal comfort was an armchair, with brad, salami, a glass of wine and a detective story. But it could also be a novel by Balzac, Dickens or Dostoevsky: the distinction between serious and popular literature did not make sense to me. With the distance of age, I am now fully aware that, despite of the apparent diversity of genres, I had always been walking into the feuilleton's territory, this kind of narrative that was born glued to journal pages to seduce readers and increase the number of copies (Sodré, 2009: 237).

In this chapter, the author advocates the importance of the feuilletonistic literature in due to its capacity of attracting lecturers, instilling onto them a taste for lecture, which does not prevent that later on these readers refine their search for more "existentialist" or aesthetically established texts. If the "serious" literature has the intention of being "true", during in time, the feuilletonistic literature, according to Sodré, wants itself "likely", touching the day-by-day superficies to entertain the lectures in an easy way. At this point, the concept of "pasticho" is used as a base to an interesting analysis of the relation between Herman Melville`s classic Moby Dick and Peter Benchley`s best-seller Jaws.

After that, Muniz Sodré points to the similarities between the journalistic narrative based on fait-divers and the whodunit literature. Mentioning other studies about the detective romances (or "novels"), as of Piglia and Pontes ones, in addition of diverse authors of this genre from past and present times, Sodré gives a panoramic view of the noir romance that serve as a great introduction to those who want to make an adventure into this type of literature: Edgar Allan Poe, Dashiell Hammet, Raymond Chandler, Patrícia Highsmith, James Lee Burke, Sue Grafton, Chester Himes, George Pelecanos, Luiz Alfredo Garcia-Roza; these are some of the mentioned names whose books are analyzed on this chapter. As it is well-known, it cannot be forgotten the name of Elmore Leonard, one of Muniz Sodré’s literacy references.

On this chapter last topic, "One Communicational Literacy", Sodré discusses the facility that detective stories have to be transcoded to other languages. This semiotic transposition, together with the facility of access that lecturers may have to pieces of this kind, according to the author, turn detective literacy into a type of "mediation literature", which means 
...a set of narrative initiation or maintenance devices of lecture taste, so much as the written forms as their transposition into audiovisual languages. It is the same as saying here a communicational literacy, understood as a "writing" committed to the act of reception or reading both on the entertainment context as on the insertion of subject-reader in a context that he should be take consciousness (Sodré, 2009: 278).

And the author finishes the book advocating for the otherness of the whodunit literature in relation to the hegemonic canon of literacy critical (including journalistic). Sodré calls the literacy critical to be more informative and less metalinguistic, proposing that the cultural journalism may play an important role on appreciation of a literature genre that was born trailer to journalistic narrative.

Munis Sodré`s most recent book becomes important for at least three different reasons: 1) presents a dense theorization about journalism as semiotic/cultural system, escaping from the logic of the deontological manuals about the journalistic making; 2) advocates in favor of an original and relational point of view, assuming similarities between the literacy narrative ("serious" and of an industrial kind) and the journalistic narrative; 3 ) demonstrates that a theoretic book may be written to please, in a sense that it may provide, beyond the reflection, the pleasure of reading usually found in the great literacy pieces.

As already said Barthes, "into the order of knowledge, onto things become what they are, what they have been, it is necessary this ingredient, the salt of words. It is this flavor of words that make knowledge deep, fertile" (Barthes, 2007: 21).

\section{Bibliographical References:}

BARTHES, Roland (2007). Aula. São Paulo: Cultrix, 95 p.

PAIVA, Raquel (2004). Muniz Sodré: perfil intelectual. In: HOHLFELDT, Antonio e GOBBI, Maria Cristina (org.). Teoria da comunicação: antologia de pesquisadores brasileiros. Porto Alegre: Sulina, p. 193-200.

SODRÉ, Muniz (2009). A narração do fato: notas para uma teoria do acontecimento. Petrópolis, RJ: Ed. Vozes, 287 p.

Pablo Laignier is a Communication PhD student at ECO/UFRJ, university at which he also obtained the degree of Master in Communication and Culture (2002), graduated in journalism (1999) and acts as researcher of LECC/UFRJ since 2007. He is also organizer and author of two chapters of the book Introduction to Communication History (E-papers, 2009). Contact: pablolaignier@yahoo.com. 
